\title{
Heart rate and arterial stiffness
}

In their recent study, Ozdogru et al. [1] concluded that the pulse wave velocity was impaired and was improved after successful percutaneous balloon valvuloplasty in patients with mitral stenosis, which reveal that mitral stenosis is a factor related to impaired arterial stiffness. However, there is an uncertainty in interpreting the results of this study.

Both structural and functional changes could affect the pulse wave velocity [2]. Among functional changes, heart rate is pretty important factors related to the pulse wave velocity. The study by Lantelme et al. [3] confirmed that heart rate had a significant relation to pulse wave velocity independent of blood pressure level. In the study by Ozdogru et al. [1], however, the baseline heart rate in mitral stenosis patients was higher than control group as stated by the authors. In addition, the changes of heart rate after successful percu- taneous balloon valvuloplasty were not described in the study by Ozdogru et al. [1]. Are there any relations of the results of the study by Ozdogru et al. [1] to the above-mentioned baseline heart rate or the changes of heart rate after successful percutaneous balloon valvuloplasty?

Conflict of interest: none declared

\section{References}

1. Ozdogru I, Celik A, Dogan A et al. Improved arterial stiffness in mitral stenosis after successful percutaneous balloon valvuloplasty. Cardiol J, 2012; 19: 586-590.

2. Guerin AP, Blacher J, Pannier B et al. Impact of aortic stiffness attenuation on survival of patients in end-stage renal failure. Circulation, 2001; 103: 987-992.

3. Lantelme P, Mestre C, Lievre M et al. Heart rate: An important confounder of pulse wave velocity assessment. Hypertension, 2002; 39: 1083-1087.

\section{Authors' response}

In our study the baseline heart rates were different in patients with mitral stenosis and conrol group as Song et al. said $(89 \pm 11$ in patients with mitral stenosis and $72 \pm 7$ in control group, $\mathrm{p}<0.001)$. But as we indicated in the result section 'No significant differences was found between heart rate at pulse wave velocity measure before and after percutaneous balloon valvuloplasty $(70 \pm 6$ and $69 \pm 5, \mathrm{p}=0.4$, respectively)'. So we did not measure the pulse wave velocity values with an average of $89 \mathrm{bpm}$ in mitral stenosis patients before percutaneous balloon valvuloplasty. We decreased the heart rates of mitral stenosis patients with medical agents and/or rest and measured the pulse wave velocity values to prevent the potential effects of higher heart rates on pulse wave velocity values.

Ahmet Celik ${ }^{1}$, Ibrahim Ozdogru ${ }^{2}$

${ }^{1}$ Department of Cardiology, Elazig Education and Research Hospital, Elazig, Turkey tel: +90 53179279 10, fax: +90 424212 14 61, e-mail:ahmetcelik39@hotmail.com

${ }^{2}$ Department of Cardiology, Erciyes University Medical Faculty, Kayseri, Turkey 